\title{
Cross-cultural Encounters and Foreign Language Learning, Assessment and Reflection: Using Digital Storytelling as an Assessment and Reflective Tool
}

\author{
Richard L. Wolfel \\ US Military Academy, West Point \\ Jeff Watson \\ US Military Academy, West Point \\ E. John Gregory \\ US Military Academy, West Point
}

\begin{abstract}
Reflection and assessment are two key issues facing intercultural competence educators and administrators alike. A digital story provides a qualitative data point to triangulate against the quantitative measures like the Intercultural Development Inventory. This triangulation is done in an effort to provide a more robust assessment of cross-cultural competence. In this research, a person's IDI score and their position on the Developmental Model of Intercultural Sensitivity are used to help understand how a person reflects on a cross cultural encounter as seen through a digital story. The points of emphasis, the quality of the reflection and the explanation of the event are strongly filtered through an individual's position on the DMIS. By linking the IDI and the digital story together, both a powerful reflection of the experience happens as well as a robust piece of programmatic assessment for a deliberate, educationally focused cross-cultural encounter.
\end{abstract}

Keywords: cross-cultural competence, assessment, study abroad, reflection

\section{INTRODUCTION}

While multiple standardized proficiency instruments exist for measuring second-language gain and cross-cultural competence, especially for longer-term immersion activities (such as semester abroad), measuring the efficacy of a shorter-term study-abroad experiences in these two areas has proven more difficult. In this study, we will demonstrate that deliberate digital storytelling can help fill the significant gap that currently exist in a comprehensive linguistic and cross-cultural assessment framework for short term, high-impact immersive learning activities. Multiple means of longitudinal assessment and comparison - both in the linguistic and cross-cultural aspects - are necessary to shape experiences to achieve the greatest level of linguistic and cross-cultural gain.

As more and more students engage in an intercultural, immersive activities as part of internationalized college curricula, three important challenges have emerged. First, the need to assess the international and cross-cultural experiences represents a growing desire to integrate these experiences into academic 
curricula and determine how the experience enhances student learning. A vast amount of work has gone into assessing such cross-cultural experiences (see Watson, Wolfel, and Siska 2013 and Watson and Wolfel 2015).

Second, a cross-cultural experience must be intentionally connected to an established program of instruction, which includes specific objectives and learning activities. It is important to place the experience within a larger educational experience in order to allow the student to come to terms with the experience and understand it within the context of previous learning. When students can link to previous experience, they begin to both understand the experience from their perspective and adjust their worldview. It is important to note that this linking of the present to the past must be accomplished through intentional curriculum development and not be left to chance or to the work of individual students.

Connecting the experience to an established program of instruction requires an understanding of where the experience fits in within the broader language and culture goals of the program. Project-Based learning (PBL) within the context of foreign language learning has been variously looked at as a form of content-based learning (Slater, et al, 2006). While various theoretical justifications and practical applications of PBL have been posited or tried, the common factor of all PBL approaches is a goaloriented approach which encourages some degree of independent thinking on the part of the learner. The intercultural experience must simultaneously be understood as a follow-on stage for which students have been deliberately prepared; it must also be understood as a deliberate stage for preparing students for what will come next in their curricular experience. Institutions must be ready to demand adjustments in the programs administered by the study-abroad partners based on longitudinal metrics. This requires that the home-institution curriculum of basic language and culture instruction be designed and delivered with the forthcoming intercultural experience in mind. Additionally, it also requires that the post-experience curriculum take full advantage of the intercultural experience because both the degradation of linguistic skills can be precipitous if the student does not continue to engage with an appropriate language-culture curriculum after he returns from the semester abroad experience (Raffaldini, 1987; Coleman, 1996). In sum, the intercultural encounter must be grounded in previous knowledge and then leveraged in follow-on educational experiences for the experience to be developmental.

Third, as a result of the need for intentionality, interest has grown in developing reflective activities for the student as part of the cross-cultural experience (Ohler, 2013; Kortegast and Boisfontaine, 2015; Marx and Moss, 2011). The vast cultural differences that confront students during an intercultural experience often lead to cognitive and social discomfort for many students. In order to cope and grow from the different environment, students must reflect and personally come to terms with the experience. Often, in order for the reflection to be successful, teacher driven reflection exercises are implemented.

In response to these insights, digital storytelling has emerged as an educational platform that builds on intentionality, mandates reflection, and provides an artifact that can be assessed. For the instructor, the digital storytelling model described below, leads to the development of guided questions for students to address in their digitally presented story. Additionally, the iterative process of story writing provides the instructor with an opportunity to guide and assure completion of specific objectives that have been intentionally developed by the instructor. For the student, the construction, production, refinement and presentation of the digital story requires them to reflect on an experience and articulate how the experience developed them. In terms of assessment, the digital story provides a critical artifact that offers a unique insight into the mindset of the student as they come to terms with a key developmental experience. While the story is important, the methods by which the student chronicles, analyzes and synthesizes the cross-cultural experience tell the teacher a great deal about the effectiveness of the program and how well the student accomplished the goals of the cross-cultural experience.

In this study, we present a proof of concept for using digital storytelling as a method of creating intentional reflection on a cross-cultural engagement. For their project, students engaging in an initial, short term (1-day) immersion experience were asked to develop a digital story discussing a cross-cultural and linguistic experience. Through this digital story, we were able to assess their experiences and link their level of analysis to their cross-cultural competence as measured by the Intercultural Development 
Inventory (IDI). The results of this study demonstrate that the storytelling process in general and as refined by the Storycenter organization, allows for unique assessment and reflection of cross-cultural experiences.

\section{Assessing Cross-cultural Experiences}

Over the last few decades, several studies have begun assessing cross-cultural experiences, especially during a study abroad experience. Some studies (Brecht, Davidson and Ginsberg, 1993; Cubillos, 2013) have emphasized language while others have exclusively looked at the influence of cross-cultural experiences on cross-cultural competence (Williams, 2005; Deardorff, 2006; Anderson, Lawton and Rexeisen, 2006). Furthermore, some studies (Vande Berg, 2012; Watson, Siska and Wolfel, 2013; Watson and Wolfel, 2015; Ingraham and Peterson, 2004; Engle and Engle, 2003; Schulz, 2007) have begun to examine language and cross-cultural competence together, emphasizing the interconnected nature of language proficiency and cross-cultural competence.

Schulz (2007: 10) draws from the National Standards for Foreign Language Learning in the $21^{\text {st }}$ century to emphasize the connection between language and culture. One of the larger issues she sees in this connection is the need to develop transdiciplinary teams and methods. In her study (2007:10), she emphasizes that some language teachers whose experience and education primarily consists of second language acquisition, while highly proficient at teaching language, lack the necessary knowledge and experience to determine relationships between cultural practices and "the cultural perspectives that gave rise to them." In other words, while such teachers may be well experienced in the language and also the cultural practices of the region, they require a transdisciplinary team to help students assess how language and cultural practices fit into the larger picture of cultural development within a specific ever-evolving region.

Hulstrand (2014) also emphasizes the multidisciplinary nature of study abroad learning in that people can study both the physical and social science aspects of a topic while abroad. She (Hulstrand, 2014: 43) discusses how students can meet with a dam manager to understand how the dam functions, then travel to a village downstream to discuss the impacts of the dam on the village, and finally travel down river by canoe to understand the environmental impacts of the dam. This is a powerful example of transdisciplinarity as people are able to synthesize new knowledge and gain a more holistic understanding of a research problem by viewing it from multiple disciplinary perspectives.

In addition to the ability to assess from multiple levels of learning, digital storytelling offers an opportunity to provide a learning and assessment activity in a transdisciplinary environment. Castaneda (2013: 63) emphasizes that digital stories allow for the "connection of knowledge across disciplines." This is critical as cross-cultural encounters are inherently interdisciplinary in nature and involve a more holistic type of learning. Digital stories will allow students to more holistically assess ideas and solve problems across the boundaries of traditional academic disciplines typically rooted in reductionism.

Additionally, Stewart (2010) demonstrates the effectiveness of e-journals as an assessment tool. The goal of her study was to "engage students in recounting their experiences of language awareness and their cultural perceptions during a semester of study abroad, in hopes of discovering how their interactions with the target language community affected their linguistic and social development" (Stewart, 2010: 141). In her study, she emphasizes the connections between cultural immersion and language proficiency, demonstrating how the two are mutually beneficial and both use an e-journal - a reflective tool - as an artifact for assessment. This is important as the dual use provides incentives for the student to complete the project to a high level of proficiency and therefore, provides authentic results. Journals, she claims, allow for a stronger personal investment as opposed to a typical assessment.

\section{Intentionality: Cross-cultural Competence in the Classroom and Beyond}

Pederson (2010: 70) emphasizes the importance of developing "intentional pedagogy" as part of the cross-cultural experience. In her study, students who had a program of cross-cultural pedagogy as part of their study abroad experience had significantly higher scores on the IDI (Pederson, 2010:76). Furthermore, she mentions that "guided reflection and exploration of one's own sense of culture allows 
the sojourner to hold a solid sense of cultural self while increasing his/her ability to navigate the complex realities of the culture of "other."' (Pederson, 2010: 77).

The use of visual imagery is another fruitful avenue for increased cross-cultural instructional opportunities. Alvaray (2014) demonstrates the use of pictures to deepen understanding of cross-cultural understanding and increasing cross-cultural dialogue. In her study, students created a photo journal showing key elements of their target culture. Alvarary (2014: 110) sees this as a reflective opportunity in which people can connect visual cues with their experience. Such reflection has been shown to be a significant tool for contextualizing the learner's experience within their intellectual development.

\section{Reflecting on Cross-cultural Encounters}

Reflection is critical to the academic success of cross-cultural encounters. Ohler (2013:9) links storytelling to reflection, emphasizing that "stories allow us to take snippets of life and put them together in ways that make it possible for us to learn and remember new things." He (2013: 9) continues to emphasize that students "need to become heroes of their own learning stories as well as the stories they tell with their own lives." Lambert 2013: 127) echoes this in his observation that "digital storytelling is a form of "reflective practice." The process of reviewing the experience and editing the story has the ability to make the author feel as if they are "thinking about people, places and objects in new ways." Digital stories provide a venue for people to make sense of complex situations and link it to other experiences.

Kortegast and Boisfontaine (2015: 812) emphasize that learning experiences are "truncated" by the post-study abroad experience available. Those with greater, and strongly directed, reflective experiences tend to "negotiate the meaning of study abroad" better than those with limited reflective opportunities. This includes greater second language acquisition, cross-cultural competence and intellectual development (Kortegast and Boisfontaine, 2015: 813). This need for reflection is echoed by DonellySmith, (2009: 14-15) in her discussion regarding the continuation of journaling exercises after the study abroad experience and her suggestion to include a one credit post-study abroad course. Similarly, Marx and Moss (2011:35) emphasize the use of intercultural guides as a source of guided reflection for intellectual development. Levy (2000) also emphasizes the importance of reflection through use of journaling and continued conversations in the post-study abroad period as significant to the continued processing of the study abroad experience.

Similarly, Pederson (2009) demonstrates improvements in cross-cultural competence as a result of intentional intervention programs before, during, and after a cross-cultural experience where students are encouraged to reflect upon cross-cultural encounters. She (Pederson, 2009: S82-S83) documents a significant increase in Intercultural Development Inventory (IDI) scores for people who participated in a cross-cultural encounter with a program of directed intervention. Directed intervention, as discussed earlier, provides opportunities for students to link the disorienting features of cross-cultural experiences to previously established cultural notions and educational frameworks.

Perry, Stoner and Tarrant (2012) emphasizes the importance of reflective experiences from a study abroad program by aligning the practice with those in general academia. Like Dewey (1938) and his emphasis on reflection in general learning, Perry et al. emphasize reflection as a way to link the past (predeparture), present (cross-cultural experience), and future (linking the experience to future coursework). They (681) emphasize the need to connect new learning experiences with personal reflection of the experience in an effort to make the experience transformative and meaningful. Learners' experiences are simply not enough; they must be combined with reflective exercises and grounded in sound pedagogy in order to bring about a transformation in the learner (680).

Walters, et al. (2011) also emphasize the importance of reflection as part of a cross-cultural experience. In their project, they use journaling and digital storytelling as the vehicles to promote reflection. They (Walters, et al., 2011: 41) refer to reflection as "the process of turning experience into learning." In other words, by connecting the experience to previously learned information, a person is able to make sense of the experience and also apply it to other life experiences. They (Walters, et al., 2011: 42) also emphasize the power of the digital storytelling narrative, in that it forces the author to instantly reflect on the experience and explain its importance to an audience. To put it more bluntly, 
"journals are for telling, digital stories are for learning" (Walters, et al. 2011: 49). The instant, and almost forced, reflection required in a digital storytelling environment is one of the great benefits of creating reflective exercises using digital stories.

Such critical reflection is an assessment of one's own beliefs in an effort to make sense of new knowledge. Sharma, et al (2011:11) refer to critical reflection as the critical process that includes "one's culture, histories, worldview and lived experiences that impacts one's personal knowledge and professional practice." As one examines their own structures, one will fit the cross-cultural experience into their own mindset or will need to evolve in order to fully appreciate the experience.

Another important aspect of reflection is its utilization as a tool for sociocultural adaptation. Antonakopoulou (2013: 60) defines sociocultural adaptation as the learning curve travelers face as they acquire new cultural knowledge to adapt to cultural change. In his study, Antonakopoulou (2013: 61) observed that students who received pre-departure training and also completed reflected essays reported less cross-cultural stress and also adapted more quickly to the new environment.

In a similar reflective endeavor, Lee (2013) utilizes blogs as a tool for reflection, emphasizing the importance of teacher-developed, intentional blogging exercises as a tool that facilitates reflection. In her study, students confirm that blogging requires them to reflect on cross-cultural encounters and facilitates an increased understanding of the event. In her study, she emphasizes the need for instructors to be actively involved in both the development process and also the peer review process in order to create activities that result in deep and meaningful reflections.

Nardon, et al. (2015) looks at another benefit of reflective activities: the creation of social support networks. In their study, they used online blogs as a method of reflecting upon cross-cultural encounters and through these online blogs, online support communities developed to help students in cross-cultural encounters come to terms and learn from the encounter. They (2015: 51) identified "three online adjustment support resources: information, interpretation and comfort." These three resources are important in the creation of communities and help shape a group's dynamics. Some will provide facts. Some members will help people understand and process the experience. Finally, others will provide emotional support for individuals in a cross-cultural encounter.

Peterson, et al (2008), emphasize the importance of group involvement in the learning process. They (2008:362) draw from the socio-constructivist approach to language learning that emphasizes the value of interaction with others and knowledge that is created as a result of these interactions. They utilize a blog approach to create the learning community and discover the effectiveness of group dynamics and interactions in creating new knowledge and fostering a deeper understanding of cross-cultural competence.

In sum, reflective exercises not only improve the key academic issues of language, cultural and intellectual development, but also allows them to make sense of the experience and place it in a meaningful personal context. This allows students to deepen their knowledge of the experience by placing it within the context of existing aspects of their worldview and by linking it to previously learned concepts. Through this contextualizing process, students move from experiences where they can describe an event to learning where they can synthesize new knowledge and also evaluate and explain the experience within the context of their worldview.

\section{Digital Storytelling as a Reflective Experience}

Unlike some of the other reflective exercises mentioned above, digital storytelling encourages a more holistic reflection by marrying aspects of digital photography, digital audio, and digital video into a whole. The use of photography as a reflective exercise has become popular in recent years. Its popularity is the result of the power of the digital image. Ross (2007:2) emphasizes the ability of the photography to "transcend linguistic and cultural differences to create a shared experience."

Furthermore, one of the key issues in the use of digital imagery as a reflective tool is the directionality of the photographer. One group (Ross, 2007) uses the concept of photovoice. Photovoice promotes growth in empathy by allowing members of a foreign culture to use cameras to take pictures of key elements of their culture. The pictures are then explained in an effort to educate people about a culture. 
The key element for the student is to view the picture and listen to the explanation in order to learn about another culture through the eyes of a local. This approach contrasts slightly with digital storytelling as described by Joe Lambert $(2013 a, 2010)$ and his colleagues at StoryCenter, a leader in the digital storytelling movement. In their model, the individual uses imagery to explain a personally defining moment. From this perspective, the student is reflecting and explaining their own experience of the other culture, as opposed to describing the other culture.

In Bjorgen (2010), another benefit of digital storytelling is that students should already have a certain familiarity with the concept. The model utilizes digital technologies that are typically quite familiar to students. As a result, they tend to open up about their transformative experiences, as they see themselves as mentors and "experts" using the technology.

Strahovnik and Mecava (2009) use stories in both directions (as the listener and as the teller) in their study. They identify several advantages to stories, one of the most important is that stories are holistic in which they not only transmit facts, but also connect facts to new meanings (Stahovnik and Mecava, 2009: 5). This amplifies one of the great strengths of stories, in that stories are able to address several levels of learning, from factual recall through the stringing of facts together to create new knowledge.

Furthermore, Yang and Wu (2012: 340) show that students who created a digital story of their crosscultural experiences show improved language proficiency, learner motivation and critical thinking. Requiring students to produce digital stories forces them to connect material from different experiences to previously learned concepts and build intellectual linkages between past concepts and the study abroad experience.

As mentioned above, the work of Joe Lambert (2013a, 2013b, 2010) and his colleagues at Storycenter has not only impacted education, but also have provided a venue for digital stories to the public health industry, migrant communities, and to other individuals and groups looking for a creative output to individually process and share their experiences. For Storycenter, the story itself, as a reflective and transformative experience, is at the center of the process and not necessarily the digital medium. Their emphasis is on providing a voice for individuals.

Lambert (2013b) emphasizes that the digital storytelling experience is a process and not a single writing session. The writing is iterative, refined and reflective. Lambert (2013b: 145) identifies seven steps of storytelling as the process of transformation that an individual goes through as they recount the event through the digital storytelling medium. This focus on transformation makes the digital story not only an artifact that demonstrates proficiency on a set of defined objectives, but also a powerful reflective experience that allows students to connect the cross-cultural experience to existing knowledge and perspectives. This connection between new and old experiences is where education and transformation happens.

\section{The Chinatown Cross-cultural Experience}

Every spring, all second-semester introductory Chinese students at the U.S. Military Academy - West Point travel to Chinatown in Flushing, Queens, New York City for an immersive activity, designed to increase their confidence in communicating in Mandarin, be immersed in the culture of the Chinese diaspora, and engage in cross-cultural interactions. Flushing is the largest Chinatown in New York City with over 200,000 citizens. The students conduct various structured activities in which they are required to interact with the local population, engaging in conversations and asking questions about the neighborhood.

In an effort to develop a reflective exercise, the students were required to identify one remarkable cross-cultural encounter that took place during the trip and produce a digital story about it. The stories were between one and two minutes long. The first part of the story described the cross-cultural encounter, who they met, where the meeting took place, and what they discussed. The second part of the

digital story required personal reflection on the experience. Here, they were expected to discuss how the experience helped them shift their perspective. What did the students learn from the encounter and how did it change their cross-cultural mindset? Ideally, students would be given pre-departure training using the Intercultural Development Continuum (IDC) to raise their awareness of the concepts. Due to time 
constraints, however, most of the instruction on digital storytelling was mostly technical in nature, emphasizing the process of creating the story, with little discussion on how best to frame their crosscultural story. Interestingly, this led to stories describing somewhat raw experiences, almost chronicling individual development as it was happening. Despite this shortcoming, almost all of the stories showed personal growth and reflection.

In addition to the digital story, the students were required to complete the Intercultural Development Inventory (IDI) in order to have a baseline cross-cultural competence profile and also provide a triangulation point for assessment data to a standardized assessment tool. The IDI is a 50-question online assessment of cross-cultural competence, that places an individual on an intercultural development continuum from a monocultural to a multicultural mindset (IDI, 2018). The IDI has undergone significant validity testing. Hammer (2011) and Hammer, Bennett and Wiseman (2003) demonstrate the psychometric validity of the IDI in their studies.

The IDI is based on Bennett's (1998) Developmental Model of Intercultural Sensitivity (DMIS) (figure 1) later modified to become the Intercultural Development Continuum. Hammer, et al (2003), describe the various orientations in the DMIS, from denial to integration. In general, Hammer, et al (2003) conclude that more monocultural (or ethnocentric) mindsets tend to avoid cultural difference, while multicultural (or ethnorelative) orientations to accept or adapt to cultural difference in their interactions. Since the IDI measures someone's cross-cultural orientation, or worldview, it provides a foundational point of departure for understanding how an individual reflects on a cross-cultural encounter. In terms of digital storytelling, one's selection and account of the cross-cultural encounter will be influenced by their worldview.

\section{FIGURE ONE APPROXIMATELY HERE}

\section{Population and Methodology}

Seventy-six students traveled to Flushing to take part in the cross-cultural exercise. Prior to departure, seventy-four of them took the IDI. The IDI results were consistent with the expectations of college sophomores. $54 \%$ percent of the students were in the denial/defense mindset. $45 \%$ were in the minimization mindset and $1 \%$ in acceptance and adaptation. This is not surprising as cross-cultural competence is an attitude and skill that is developed over a lifetime. Someone who is around 20 years old has not fully matured yet and cannot be expected to have finished developing their cross-cultural competence.

As mentioned above, in addition to the IDI, students also completed a digital story upon return. The assignment required them to complete a digital story using digital images and audio (video optional) that focused on a significant cultural encounter during the trip and then present their digital story video in class to their instructor and peers. A rubric was developed to assess their video. The rubric (figure 2) was based on a general education curriculum goal for the Academy: "Engage in and reflect upon crosscultural experiences." This rubric was developed using the Association of American Colleges and Universities Intercultural Knowledge and Competence VALUE rubric (AAC\&U, 2014) and the Developmental Model of Intercultural Sensitivity (Bennett, 1993). The result was a three-level rubric in which students would exceed, meet or not meet the standard. The rubric, like the standard, was divided in half, first looking at the willingness to engage in cross-cultural encounters and second at a student's ability to reflect. Assessment occurs on whether the reflection was through the lens of their own cultural identity, or if they attempted to shift perspectives and view things as more dynamic and less static. The rubric was not used for any grading purposes, and was not shared with the students at any point during the exercise. Given the personal nature of the digital story, we wanted the students to feel unconstrained by evaluation and the only grade they received was for completion of the digital story. The rubric was exclusively used for assessment of the exercise and the curriculum. 


\section{FIGURE 2 APPROXIMATELY HERE}

\section{Findings}

Based on the rubric, most of the students $(63 \%)$ met the standards. They were willing to engage in cross-cultural encounters and most reflected on the experience, albeit somewhat hesitantly and mostly through the lens of their own worldview. $35 \%$ of the students did not meet the standard, either by not engaging in a cross-cultural encounter or not reflecting upon the experience. Finally, one student (2\%) exceeded the goal standard. Their video showed them actively searching out cross-cultural encounters, using humor during their conversation with the local population to build rapport, showing a higher level of comfort in cross-cultural encounters, and providing a reflection that began to shift perspectives and view the encounter from both their own worldview and the view of the local population.

\section{Discussion: 3C Characteristics and Triangulation to the IDI}

Together, it is expected that a student's digital story should be influenced by their position on the DMIS, as measured by the IDI. This was found to be accurate when digital stories were compared to an individual's IDI scores. Our hypothesis was that the themes and language used in the digital story should be indicative of their level of cross-cultural development.

The themes in the digital stories were indeed consistent with the level of cross-cultural competence development as measured in the IDI. Students who demonstrated a monocultural (denial/defense) mindset tended to explain the cross-cultural encounter from their own perspective. They often emphasized differences between groups, describing the event as a "cultural adventure," and viewing things from a tourist perspective. One student stated that he observed, "Chinese people doing Chinese things during the day." Others saw the event as an opportunity to practice language and assessed their success based on an improvement in their Chinese language skills. Most of the students in this group tended to complete the requirements for the assignment but did not go beyond the requirements. Several of them mentioned staying within their comfort zone, an indicator that a perspective shift did not fully occur.

All these observations are consistent with individuals in a monocultural mindset. There is a desire to stay within one's comfort zone: Viewing cultural difference from a polarizing, "us vs them" position. Many of them noted a Chinese way of doing things versus the American way of doing them.

The students in a minimization mindset created videos that emphasized similarities as opposed to differences and emphasized universality and commonality in their discussions. They were interested in engaging in cross-cultural encounters and saw value beyond practicing their language skills or participating in tourist-type activities.

Students in the minimization mindset looked at people as welcoming, looked for similarities between them and the local population. Some looked to find familiarity within the Chinese community as an effort to make sense of the experience. Some emphasized hard work as a unifying characteristic between Americans and Chinese. Often, the students in a minimization mindset emphasized that they thought the Chinese population was very "friendly and hard working." The definitions of friendly and hardworking, however, were from the cultural perspective of the student and not from the diaspora. In other words, the students applied their definitions of friendly and hardworking to the citizens with little consideration or discussion of how these concepts (or other concepts for that matter) could differ in different cultural contexts. They saw the concepts of friendly and hardworking as universal, both in terms of the concept and how the concept is defined.

The one cadet who demonstrated a multicultural mindset on the IDI (falling in the Acceptance/Adaptation range) produced a video that demonstrated his ability to act as an intercultural bridge. In his video, he used humor as a method of bridging cultural difference. He tried to tell humorous stories and jokes with local Chinese population and demonstrated a comfort in his interactions. This ability to assess the 'other' and adapt their behavior to better engage in cross-cultural activities is quite indicative of a multicultural mindset. 
Another clear finding of this study is that digital storytelling, even after a very short immersion experience, provides an assessment artifact that can be triangulated against other assessment activities. As demonstrated here, one's worldview has a profound impact on how they observe and reflect on crosscultural encounters. As a result, one's digital story of a cross-cultural encounter should correlate to their cross-cultural perspective. By looking at the selected imagery and listening to the student's description of the event, certain patterns developed. These patterns fell readily into the various orientations measured by the IDI and visualized on the DMIS. Students in a monocultural mindset tended to emphasize difference between cultures and their interactions were somewhat forced by the requirements of the assignment. When they reflected on the experience, most of the reflection focused on how the culture of the Chinese diaspora was different from their own, how the experience helped them with the language skills, and how the region was "exotic" or was a destination for them to consume a unique culture. Most of the videos in this section tended to show images of the Chinese population separate from the American students, not showing interactions, but emphasizing sites in the neighborhood like a tourist might.

As the students started approaching the cusp of the minimization orientation in their IDI scores, they started seeking out commonalities, consistent with individuals in a minimization mindset. The images and videos here discussed and showed interactions between students and the local population. They tended to embrace the chaos and dissonance of the experience more than others. Some saw it as an opportunity to put their language skills into action in order to increase their knowledge of the region. For these students, the majority of their stories tended to emphasize similarities between cultures, like hard work and friendliness. They saw these characteristics as universal and not filtered through a cultural lens, while subconsciously filtering it through a definition derived from their own cultural mindset. Their videos tended to show interactions more often than scenes from the local neighborhood, indicating their appreciation of the cross-cultural interactions as part of the experience. In their reflection, they emphasized how much they shared in common and how language helped facilitate interaction and increased cultural knowledge.

Overall, these scores were consistent with the students' levels of interaction with Chinese culture. Most of the students had only completed two semesters of Chinese, did not have any Chinese heritage background, and had never previously traveled to China. They could engage in basic conversations and had, to varying degrees, experienced two full semesters of basic Chinese language instruction. Most, but not all, of the students had native Chinese faculty members as instructors. Under these circumstances, the level of cross-cultural competency reflected in both the IDI scores and the videos was consistent with what the researchers anticipated.

\section{ANALYSIS AND IMPLICATIONS}

This study emphasized three key challenges of incorporating cross-cultural encounters into the curriculum. First is reflection. One of the great strengths of digital storytelling is the inherently reflective nature of the final project. Through the intentionality of the assignment, students were required to select a transformative experience. Findings in this study further support those in Pederson (2009),Perry, Stoner and Tarrant (2012), and Kortegast and Boisfontaine (2015) who emphasize the importance of reflection as a method of increasing the meaningfulness of the cross-cultural experience and linking the experience to students' prior experience in an effort to increase learning. Joe Lambert (2013b) places transformation at the core of the Storycenter Project and digital storytelling experience. This use of reflection as a method of linking to prior experience is common across the videos as students across all orientations often reach to previous experiences to explain their observations and experiences in Flushing, or how their expectations going into the Flushing experience did not meet reality. This link to previous knowledge helped contextualize the experience and increase their cross-cultural development.

Another key reflective characteristic of the digital storytelling experience is the group sharing aspect in class following the trip. Strahovnik and Mecava (2009) emphasize that learning occurs in both directions, both as the producer and consumer of digital stories. While this study emphasized the production side, when the students showed their videos in their classroom in a small group forum, the 
richness of the discussions and questions from peers demonstrated support for Strahovnik and Mecava's (2009) research and the weight they place on bidirectional learning as a result of both producing and watching videos. This is also emphasized by Lambert $(2013 a, 2013 b, 2010)$ in his development of the story circle approach to storytelling. The sharing in a small group experience not only creates an intimate setting for individuals to share their stories, but also creates a setting for people to learn as they listen to the experience of other students.

The second major challenge educators face in implementing cross-cultural encounters into the curriculum is the development of learning exercises that intentionally direct learning and reflection during an cross-cultural experience. Pederson (2010: 70) emphasizes the importance of developing "intentional pedagogy" as part of the cross-cultural experience and demonstrates that cross-cultural competency is increased as a result of intentional pedagogical experiences that are tied to the cross-cultural experience. Digital storytelling allows for intentionality. By creating a specific assignment and learning process, and by placing students in a specific cross-cultural context, instructors activated a certain pedagogical framework and forced students to engage within that framework. In this framework, learning occurred through conversations between instructor and student through student to student interactions that occur in the story circle environment.

Finally, assessment of the cross-cultural experience is the third challenge instructors face. Crosscultural encounters are inherently interdisciplinary and represent a type of holistic learning that requires instruction and assessment from multiple disciplinary perspectives in order to foster the most beneficial learning and developmental experiences. Castaneda (2013: 63) emphasizes that digital stories allow for the "connection of knowledge across disciplines." The connection of information technologies to the humanities is one of the great strengths of digital storytelling. Students are required to go through a creative writing process with intentionality, to produce a script for the story. Once the script is complete, they utilize various forms of technology and media in order to produce the digital story, which is both auditory and visual in its presentation. Digital stories sit at multiple interdisciplinary points and provides an intentional pedagogy that requires students to think beyond not only traditional disciplinary boundaries, but also requires them to utilize multiple forms of expression to reach conclusions and synthesize knowledge holistically.

\section{CONCLUSIONS}

Digital storytelling provides an experience that allows for purposeful curriculum development, reflection, and assessment. The construction of an iterative story allows for directed instruction, around issues deemed significant by the instructor. The exercise is reflective as it requires a student to think back on an experience, connect it with past, present, and future learning, and explain the experience and its significance to an audience. Finally, digital stories are assessable. The stories provide artifacts, through the spoken word and imagery, that demonstrate achievement of an educational objective.

As the popularity and accessibility of cross-cultural encounters continue to grow in number and popularity, the quality of the encounters will continue to be scrutinized. Quality programs tend to share the three abovementioned key characteristics: they are built as part of a purposeful curriculum, they emphasize reflection on many levels, and they are assessable. Therefore, it is essential as we build crosscultural experiences, we keep these three characteristics at the forefront of planning.

In the end, this qualitative study is not presented as a definitive study, but is intended as an invitation to build on this research and to demonstrate proof of the concept that digital storytelling as a directed reflective experience is worthwhile and highly beneficial to promoting increased cross-cultural competence after an immersion experience in an internationalized college curriculum. 


\section{REFERENCES}

Alvaray, L. (2014). Snap shots: Using photography for intercultural awareness and understanding. Communication Teacher, 28(2), 109-116.

Anderson, P. H., Lawton, L., Rexeisen, R., \& Hubbard, A. C. (2006). Short-term study abroad and intercultural sensitivity: A pilot study. International Journal of Intercultural Relations, 30(4), 457-469.

Antonakopoulou, E. (2013). Sociocultural Adaptation of US Education Abroad Students in Greece: The Effects of Program Duration and Intervention. Frontiers: The Interdisciplinary Journal of Study Abroad, 23, 60-72.

Bennett, M. J. (1998). Developmental model of intercultural sensitivity. John Wiley \& Sons, Inc.

Berg, M. V., Paige, R. M., \& Lou, K. H. (2012). Student Learning Abroad: What Our Students Are Learning, What They? re Not, and What We Can Do About It. Stylus Publishing, LLC.

Bjørgen, A. M. (2010). Boundary crossing and learning identities-digital storytelling in primary schools. Seminar. Net, 6(2).

Brecht, R., Davidson, D., \& Ginsberg, R. (1995). Predictors of foreign language gain during study abroad. Second Language Acquisition in a Study Abroad Context, 9(37).

Castañeda, M. E. (2013). I am proud that I did it and it's a piece of me: Digital storytelling in the foreign language classroom. CALICO Journal, 30(1), 44-62.

Coleman, J. (1996). A comparative survey of the proficiency and progress of language learners in British universities. In Der C-Test. Theoretische Grundlagen und prakische Anwendungen (ed. by R. Grotjahn, volume 3, pp. 367-399.). Bochum, Brockmeyer.

Cubillos, J. H. (2013). Community engagement and proficiency gains in short-term study abroad programs. NECTFL Review, 71.

Deardorff, D. K. (2006). Assessing intercultural competence in study abroad students. Languages for Intercultural Communication and Education, 12, 232.

Dewey, J. (1938). Experience and education. New York: Collier Books, Macmillan.

Donelly-Smith, L. (2009). Global Learning Through Short-Term Study Abroad. Peer Review, 11(4), 1215

Engle, L., \& Engle, J. (2003). Study abroad levels: Toward a classification of program types. Frontiers: The Interdisciplinary Journal of Study Abroad, 9(1), 1-20.

Hammer, M. R. (2011). Additional cross-cultural validity testing of the Intercultural Development Inventory. International Journal of Intercultural Relations, 35(4), 474-487.

Hammer, M. R., Bennett, M. J., \& Wiseman, R. (2003). Measuring intercultural sensitivity: The intercultural development inventory. International Journal of Intercultural Relations, 27(4), 421443.

Hulstrand, J. (2014). Multidisciplinary programs abroad. International Educator, 23(6), 40.

IDI. (n.d.). The Intercultural Development Continuum. Retrieved from https://idiinventory.com/products/the-intercultural-development-continuum-idc/.

Ingraham, E. C., \& Peterson, D. L. (2004). Assessing the impact of study abroad on student learning at Michigan State University. Frontiers: The Interdisciplinary Journal of Study Abroad, 10, 83-100.

Kortegast, C. A., \& Boisfontaine, M. T. (2015). Beyond "It Was Good": Students' Post-Study Abroad Practices for Negotiating Meaning. Journal of College Student Development, 56(8), 812-828.

Lambert, J. (2010). Digital storytelling cookbook. Digital Diner Press.

Lambert, J. (2013). Digital storytelling: Capturing lives, creating community. Routledge.

Lambert, J. (2013). Seven stages: Story and the human experience. Digital Diner Press.

Lee, L. (2010). Fostering reflective writing and interactive exchange through blogging in an advanced language course. ReCALL, 22(2), 212-227.

Levy, D. (2000). The shock of the strange, the shock of the familiar: Learning from study abroad. Retrieved from https://digitalcommons.unl.edu/cgi/viewcontent.cgi?article=1192\&context=nchcjournal . 
Marx, H., \& Moss, D. M. (2011). Please mind the culture gap: Intercultural development during a teacher education study abroad program. Journal of Teacher Education, 62(1), 35-47.

Nardon, L., Aten K., \& Gulanowski, D. (2015). Expatriate adjustment in the digital age: The co-creation of online social support resources through blogging. International Journal of Intercultural Relations, 47, 41-55.

Ohler, J. B. (2010). Digital storytelling in the classroom: New media pathways to literacy, learning, and creativity. Corwin Press.

Pedersen, P. J. (2010). Assessing intercultural effectiveness outcomes in a year-long study abroad program. International Journal of Intercultural Relations, 34, 70-80.

Perry, L., Stoner, L., \& Tarrant, M. (2012). More than a vacation: Short-term study abroad as a critically reflective, transformative learning experience. Creative Education, 3(5), 679.

Petersen, S. A., Divitini, M. \& Chabert, G. (2008). Identity, sense of community and connectedness in a community of mobile language learners. ReCALL, 20(3), 361-379.

Raffaldini, T. (1987). Attrition of communicative ability among former year abroad students of French. Unpublished doctoral dissertation, Indiana University, Bloomington, IN.

Ross, S. T. (2011). Show and tell: Photovoice as international travel pedagogy. Analytic Teaching and Philosophical Praxis, 32(1).

Schulz, R. A. (2007). The challenge of assessing cultural understanding in the context of foreign language instruction. Foreign Language Annals, 40(1), 9-26.

Sharma, S., Phillion, J., \& Malewski, E. (2011). Examining the Practice of Critical Reflection for Developing Pre-Service Teachers' Multicultural Competencies: Findings from a Study Abroad Program in Honduras. Issues in Teacher Education, 20(2), 9-22.

Slater, T., Beckett, G. H., \& Aufderhaar, C. (2006). Assessing projects as second language and content learning. Project-based Second and Foreign Language Education: Past, Present, and Future, 241-260.

Stewart, J. A. (2010). Using e-Journals to Assess Students' Language Awareness and Social Identity During Study Abroad. Foreign Language Annals, 43(1), 138-159.

Strahovnik, V., \& Mecava, B. (2009). Storytelling and Web 2.0 services: A synthesis of old and new ways of learning. eLearning Papers, 15, 1-11.

Walters, L. M., Green, M. R., Wang, L., \& Walters, T. (2011). From heads to hearts: Digital stories as reflection artifacts of teachers' international experience. Issues in Teacher Education, 20(2), 37.

Watson, J. R., Siska, P., \& Wolfel, R. L. (2013). Assessing gains in language proficiency, cross-cultural competence, and regional awareness during study abroad: A preliminary study. Foreign Language Annals, 46(1), 62-79.

Watson, J. R., \& Wolfel, R. (2015). The intersection of language and culture in study abroad: Assessment and analysis of study abroad outcomes. Frontiers: The Interdisciplinary Journal of Study Abroad, $25,57-72$.

Williams, T. R. (2005). Exploring the impact of study abroad on students' intercultural communication skills: Adaptability and sensitivity. Journal of Studies in International Education, 9(4), 356-371.

Yang, Y. C., \& W, W. I. (2012). Digital storytelling for enhancing student academic achievement, critical thinking, and learning motivation: A year-long experimental study. Computers \& Education, $59(2), 339-352$. 


\title{
APPENDIX
}

\section{FIGURE 1 DEVELOPMENTAL MODEL OF INTERCULTURAL SENSITIVITY}

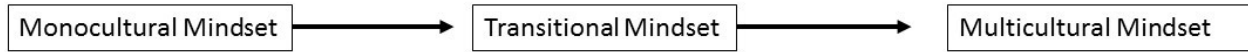

\begin{tabular}{|l|l|l|l|}
\hline Denial & Defense/Polarization & Acceptance Adaptation & Integration \\
\hline
\end{tabular}

\section{FIGURE 2}

RUBRIC FOR CROSS CULTURAL COMPETENCE

\begin{abstract}
Standard 6.4: Engage in and reflect on cross cultural experiences.
Doesn't Meet: Recognizes the experience of others but does so through one's own cultural worldview.

Demonstrates little to no desire to engage in cross culture experiences. Shows little demonstrable reflection on any engagements.

Meets: Engages in cross cultural experiences hesitantly. If prompted, shows a willingness to reflect on the experience, articulating the strengths and challenges within specific experiences to increase one's effectiveness in different contexts.

Exceeds: Actively seeks out and engages in cross cultural opportunities. Continuously reflects on cross

cultural experiences, evaluating changes in one's own learning over time and developing improved

methods of engagement .
\end{abstract}

134 Journal of Higher Education Theory and Practice Vol. 20(2) 2020 